\title{
A Review on Marathi Language Speech Database Development for Automatic Speech Recognition (ASR) System.
}

\author{
Mrs. Chhaya S. Patil ${ }^{1}$, Prof.Dr.Vaishali B.Patil ${ }^{2}$, \\ ${ }^{1}$ Assistant Professor, R.C.P.E.T. 's Institute of Management Research \& Development, Shirpur. \\ ${ }^{2}$ Associate Professor, R.C.P.E.T.'s Institute of Management Research \& Development, Shirpur.
}

\section{ABSTRACT}

Speech is a natural means of communication between humans. Human being tried to develop computer that can understand \& talk like human. Digital content can research to the masses \& facilitate the exchange of information across peoples speaking different language in form of natural interface provided by language technologies. Developing certain recognition system standard, speech database is a prerequisite. There is lot of scope to develop automatic speech recognition (ASR) system using Indian languages which are of different variations. This paper present review on speech database developed for Marathi language.

Keywords: Automatic speech Recognition, corpus, speech database, Isolated Words, Marathi

\section{INTROUDUCTION}

Information in digital world is accessible to a few who can read or understand a particular language. India has about 1652 dialects/ native languages, in such multi-lingual society language technologies play a crucial role. Speech recognition, machine translation \& speech synthesis system could facilitate the exchange of information between two people speaking two different languages [1] The paper gives the review on speech database developed in Marathi language. This review would be helpful for researches that are willing working in domain of automatic speech recognition (ASR) system \& speech processing in Marathi language \& various dialects of it. The paper is organized as follows: Section II describe about Marathi language Section III describe the various speech database developed in Marathi language section IV gives conclusion \& future work followed by references.

\section{MARATHI LANGUAGE}

Indian constitution recognizes 23 languages Marathi is one of them. Marathi is written in Devanagri script. These languages have been derived from Sanskrit which is also written in Devanagri script. Standard Marathi is as the official language in 35 different districts of Maharashtra state. Standard Marathi \& Warahadi Marathi is major dialect of Marathi. Academics \& print media use Standard Marathi dialects. 42 characters of spoken Marathi were distinguished by the Indic scholars [5]

\section{MARATHI SPEECH DATABASE}

IIIT - Hyderabad with co-ordination of HP lab Bangalore developed speech database for various Indian languages including Marathi. This database developed for large vocabulary speech Recognition systems. CIIL corpus of Marathi language was used for text corpus collection [12]. The speech data was recorded over calculated number of landline \& cellular phones using a multi-channel computer telephony interface card .Four different cell phones were use to capture different micro phonic variations. Following table 1 shows number of speakers were selected.

Table 1: Number of speaker

\begin{tabular}{|l|l|l|l|}
\hline Language & Landline & $\begin{array}{l}\text { Cell } \\
\text { phone }\end{array}$ & Total \\
\hline Marathi & 92 & 84 & 176 \\
\hline
\end{tabular}

Table 2 \& 3 Shows age wise \& gender wise distribution of speaker

\begin{tabular}{|l|l|l|l|l|l|}
\hline Language & $18-30$ & $30-40$ & $40-50$ & $50-60$ & $>60$ \\
\hline Marathi & 77 & 56 & 26 & 12 & 5 \\
\hline
\end{tabular}

Table 3: Age wise Speaker distribution

\begin{tabular}{|l|l|l|}
\hline Language & Male & Female \\
\hline Marathi & 91 & 85 \\
\hline
\end{tabular}


52 sentences of the optimal text was recorded by each speaker .The transcriptions were manually edited collected data \& ranked base on the goodness of the speech recorded " Good ","with channel distorting"," with background noise" \& "useless" these were categories of utterances [1]. IIIT-Hyderabad also developed speech database for major Indian languages, Marathi is one of them [6]. The purpose of developing the IIT-H Indic speech databases was to have speech \& text corpora made available in public domain, without copyright restrictions for non- commercial \& commercial use [6]. Text corpora were selected from Wikipedia dump of Indian languages released in 2008. Native speaker were selected for recording purpose. The age of speakers were 20-30 years. 1000 phonetically balanced sentences were selected form text corpus. A single wave file has 50 utterances [6]

TIFR (Mumbai) \& IIT Bombay together developed a speech database for agriculture purpose. This Project sanctioned by the technology development for Indian languages (TDIL) for the development of speech recognition system for using cell phones \& landline. TIFR Mumbai \& IIT Bombay collected the speech data using two dedicated phone line. Two volunteers were appointed for the development of database. Volunteers visited the various districts of Maharashtra \& speech sample collected the by calling thru the dedicated phone line. Speech sample were collected from 1600 speakers approximately. As recording was done using phone line having narrow band \& speech along with background noise, to overcome this difficulty Volunteers also used digital voice recorder. [2]

IIT-Khargpur also developed speech database for text independent speaker identification in ASR. Recording frequency was $22,500 \mathrm{~Hz}$, mono channel, 16 bit resolution \& 10 utterances. The recording was done in various environment conditions like road home, office, slums, college, train, hills, valleys, remote villages, research labs $\&$ farms. The total numbers of speakers were 60 [13]. A noticeable works also done at Dr. B.A.M university Aurangabad by department of computer science \& IT the speech database developed for limited vocabulary continuous speech database \& two different isolated speech database for agricultures \& travel purpose of Aurangabad \& speech database of numbers in Marathi language. Following table shows summarized information about these speech databases.

Table 4: Gender wise Speaker distribution

\begin{tabular}{|c|c|c|c|c|c|c|c|c|}
\hline $\begin{array}{l}\text { Speech Database } \\
\text { Purpose }\end{array}$ & \multicolumn{2}{|c|}{$\begin{array}{l}\text { No. Of } \\
\text { Speaker }\end{array}$} & Age & $\begin{array}{l}\text { No. of } \\
\text { Words }\end{array}$ & Words used for Recording & $\begin{array}{l}\text { No of } \\
\text { Utterance }\end{array}$ & $\begin{array}{l}\text { Sampling } \\
\text { Frequency, } \\
\text { Channel }\end{array}$ & $\begin{array}{l}\text { Total } \\
\text { Utterances }\end{array}$ \\
\hline \multirow{3}{*}{$\begin{array}{l}1 . \quad \text { Isolated } \\
\text { Numeric Speech } \\
\text { database }\end{array}$} & \multicolumn{2}{|c|}{160} & \multirow{3}{*}{$\begin{array}{l}20-55 \\
\text { Years }\end{array}$} & \multirow[t]{3}{*}{10} & \multirow[t]{3}{*}{ Marathi Number 0 to 9} & \multirow[t]{3}{*}{5} & \multirow{3}{*}{$\begin{array}{l}1600 \mathrm{~Hz}, 16 \\
\text { bit mono }\end{array}$} & \multirow[t]{3}{*}{8000} \\
\hline & $\mathrm{M}$ & $F$ & & & & & & \\
\hline & 80 & 80 & & & & & & \\
\hline \multirow{3}{*}{$\begin{array}{l}\text { 2. Isolated word } \\
\text { speech database }\end{array}$} & \multicolumn{2}{|c|}{100} & \multirow{3}{*}{$\begin{array}{l}20-55 \\
\text { Years }\end{array}$} & \multirow[t]{3}{*}{120} & \multirow{3}{*}{$\begin{array}{l}\text { Tourism Recreational Historical } \\
\text { Religious places }\end{array}$} & \multirow[t]{3}{*}{3} & \multirow{3}{*}{$\begin{array}{l}1600 \mathrm{~Hz}, 16 \\
\text { bit mono }\end{array}$} & \multirow[t]{3}{*}{36000} \\
\hline & $\mathrm{M}$ & $\mathrm{F}$ & & & & & & \\
\hline & 50 & 50 & & & & & & \\
\hline \multirow{3}{*}{$\begin{array}{l}\text { 3. Isolated word } \\
\text { for agriculture } \\
\text { purpose }\end{array}$} & 100 & & \multirow{3}{*}{$\begin{array}{l}20-55 \\
\text { Years }\end{array}$} & \multirow[t]{3}{*}{100} & \multirow{3}{*}{ 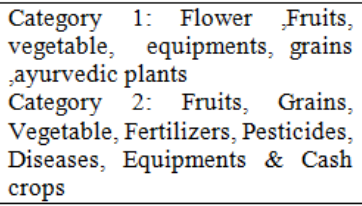 } & \multirow[t]{3}{*}{3} & \multirow{3}{*}{$\begin{array}{l}1600 \mathrm{~Hz}, 16 \\
\text { bit mono }\end{array}$} & \multirow[t]{3}{*}{60000} \\
\hline & $\mathrm{M}$ & $\mathrm{F}$ & & & & & & \\
\hline & 50 & 50 & & & & & & \\
\hline $\begin{array}{l}\text { 4.Continuous } \\
\text { speech data base } \\
\text { for agriculture } \\
\text { purpose }\end{array}$ & \multicolumn{2}{|c|}{1440} & $\begin{array}{l}20-55 \\
\text { Years }\end{array}$ & $\begin{array}{l}55 \text { to } 66 \\
\text { Sentences }\end{array}$ & $\begin{array}{l}\text { Continuous sentences regarding } \\
\text { various crops }\end{array}$ & ----- & $\begin{array}{l}1600 \mathrm{~Hz}, 16 \\
\text { bit mono }\end{array}$ & 36864 \\
\hline
\end{tabular}

The Isolated words \& Sentences were selected from various blogs, news articles, forums $\&$ websites over the internet. The speech sample was collected from four districts i.e. Aurangabad Jalana, Beed \& Osmanabad of Marathwada region [5]. PRAAT software was used for recording speech \& speech sample captured using Sennheiser headsets.

The speech database for Marathi isolated word recognition was developed at Dr. B.A.M. University supported by DST under fast track scheme entitle is "Design \& development of Marathi speech interface system".
The vocabulary size of the database consist of

1) Marathi Vowels : 105 samples

2) Isolated words starting with each vowel : 420 samples

3) Sentences : 175 sample

The total no of speaker was 35 out of which 17 were Females \& 18 were males having age from 22 to 35 years. High quality of audio recording achieved by noise free $\&$ echo free room having size 10x10. The sampling frequency was $11025 \mathrm{~Hz} \&$ the recording was done using Computerized speech laboratory (CSL) using the single Channel [4] Isolated Marathi words 
emotional speech database developed for robust automatic speech recognition (ASR) system \& for robotics. It also developed at Dr B.A.M University supported by UGC as Major research project. Basic $\&$ most commonly observed emotional like happy, sad \& angry were selected. Speech sample collected from 25 male \& 25 female speakers having age group of 21 to 40 .The total no of words were 24 with 3 utterances each. The total size of utterance was 3600. In normal environment data was recorded .PRAAT is used for recording \& speech in captured using Sennheiser headset. The sampling rate was $1600 \mathrm{~Hz}$ \& five is in 16 bit more audio format [11].

Speech database of medicinal plants names was developed by Dr. B.A.M University supported by UGC for ASR of isolated Marathi words .This database helpful in agriculture field as well to medical student. Number of words was 100, category of words were Medicinal plants which growth in India, number of speaker were 100, speakers age between 20 to 50 \& Speaker from Aurangabad region. Numbers of Utterances were 3, total utterances were 30,000. Recording software was PRAAT \& Sampling frequency rate was 16 $\mathrm{kHz}$. File format was .wav .Recording done using Sennheiser Headset [9]

\section{CONCLUSION}

In this paper we have discussed some of the speech databases developed in Marathi language for various applications. After studying the developed speech database we have been motivated to developed isolated words speech database for agriculture purpose in Ahirani dialect.

\section{REFERENCES}

[1]. Rohit kumar, S.P. Kishore, Anuman chipalli Gopalkrishna, Rahul chitturi, sachin joshi, satinder singh, R.N.V sitaram, Development of Indian language speech database for large vocabulary speech recognition system proceedings of International conference on speech \& computer (SPECOM) , Patras, Grees oct 2005.

[2]. Pukhraj P. Shrishrimal, Ratnadep R. Deshmukh, Vishal B.Waghmare "Indian Language speech database : Review “ Internal journal of computer application (0925-888), volume 47-No. 5 june 2012
[3]. Yogesh K. Gedam, Paras V.Kothare, Ratnadeep R. Deshmukh "Design \& development Speech database of Marathi Numerals "Innternational journal of Adanced Research In Maerch 2013 .Computer science s/w Engineering volume 4 Issue-3

[4]. Bharati W. Gawali, santosh Gaikwad , Pravin annawar, suresh c, Mehrotra “ Marathi Isolated word recognition system using MFCC \& DTW Features "Proc of Inc conf. on advances in computer science 2010

[5]. Pukhraj P shrishrimal, Ratnadeep R Deshmukh Ganesh B. Janvave, "Development of Marathi" Language speech database from Marathwada Region"

[6]. Kishore Prahllad, E naresh kumar, Venketesh keri, S Rajendran, Alan W Black " The IIT-H indic speech databases".

[7]. Pooja v janse al, Design \& development of speech database for Travel purpose in Marathi International journal of computer science \& mobile computing, vol3 issue 7,May 2014, pg.872-875.

[8]. [8] V.B.Waghmare, R.R Deshmukh , P.P Shrishmal G.B. Janvale, "Development of Isolated Marathi international journal of computer applications. (0975-8887) volume 94 no. 4 May 2014

[9]. Kishori R Ghule Ratnadeep R. Deshmukh, "Automatic speech reconition of Marathi isolated journal of computer science \& Information Technology vol.6 65), 2015 4296-4298.

[10]. P.P. Shrishrimal ,Ratnadep R. Deshmukh ,vishal B Loaghmane, "Marathi Isolated words speech database for Agriculture purpose", International Journal of Engineering Innovation \& Research volume-3 Issue 3 ,ISSN : 2277-5668

[11]. V.B Waghmare, R.R.Deshmukh, P.P. Shrishrimal, G.B. Janvale "Development of Isolated Marathi words Emotional speech database", Intemational journal of Computer Application (0975-8887) volume 94-No.4,May 2014

[12]. "http://tdil.mit.gov.in/corpora/achcorpora.htm\#tech" Marathi CIIL corpus

[13]. https://www.ldc.upenn.edu/sites/www.ldc. upenn.edu/files/agrawal2008.pdf 